\title{
Hereditary diffuse leukoencephalopathy with axonal spheroids and pigmented glia
}

INSERM

\section{Source}

INSERM. (1999). Orphanet: an online rare disease and orphan drug data base. Hereditary diffuse leukoencephalopathy with axonal spheroids and pigmented glia. ORPHA:313808

Hereditary diffuse leukoencephalopathy with axonal spheroids and pigmented glia is a rare autosomal dominant disease characterized by a complex phenotype including progressive dementia, apraxia, apathy, impaired balance, parkinsonism, spasticity and epilepsy. 